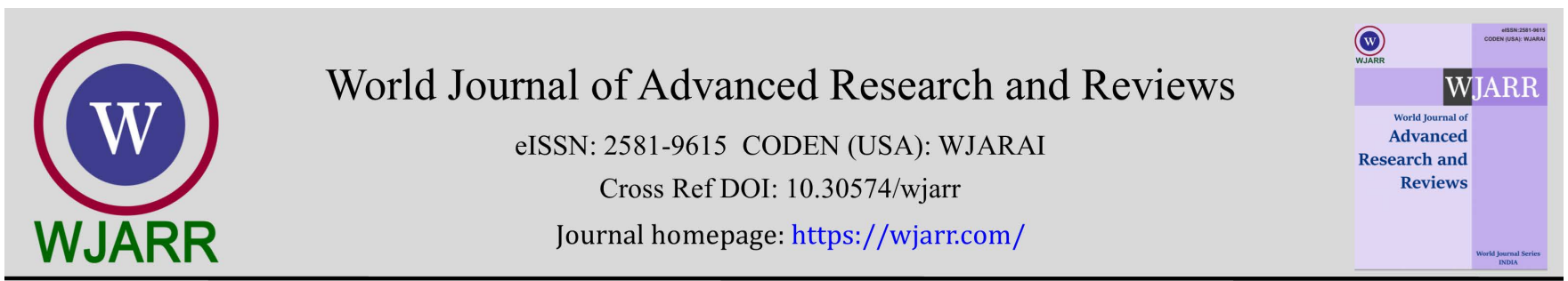

(RESEARCH ARTiClE)

Check for updates

\title{
The evaluation of urinary vanillylmandelic acid level in patients with generalized anxiety disorder
}

Farzana Yeasmin Mukta 1, ${ }^{*}$, Qazi Shamima Akhter 2, Shamanta Islam ${ }^{3}$, Khushbun Nahar Layla 4 , Afrina Binte Azad ${ }^{5}$, Kazi Lutfar Rahman ${ }^{6}$, Sudipta Sarker ${ }^{7}$ and Syed Tasin Bin Shahid ${ }^{8}$

${ }^{1}$ Department of Cardiology, Kurmitola General Hospital, Cantonment, Dhaka, Bangladesh.

2 Department of Physiology, Dhaka Medical College, Dhaka, Bangladesh.

${ }^{3}$ Bhairab Upazila Health Complex, Kishorgonj, Bangladesh.

${ }^{4}$ Department of Physiology, Ibrahim Medical College and Hospital, Dhaka, Bangladesh.

${ }^{5}$ Department of Physiotherapy, National Institute of Traumatology and Orthopaedic Rehabilitation, Dhaka, Bangladesh.

${ }^{6}$ Rt- PCR lab, Kurmitola General Hospital, Cantonment, Dhaka, Bangladesh.

${ }^{7}$ Charbaria Union Health and Family Welfare Centre, Barishal, Bangladesh.

${ }^{8}$ Epsom and st helier nhs trust, Epsom, London, UK.

World Journal of Advanced Research and Reviews, 2021, 12(01), 001-005

Publication history: Received on 23 August 2021; revised on 26 September 2021; accepted on 28 September 2021

Article DOI: https://doi.org/10.30574/wjarr.2021.12.1.0482

\begin{abstract}
Background and objectives: The prevalence of anxiety disorders is increasing in the world. Studies revealed that generalized anxiety disorder may lead to change in circulating catecholamine levels. Thus, the changes of catecholamine metabolite like urinary vanillylmandelic acid may increase the future risk of thrombotic diseases in patients with generalized anxiety disorder (GAD). The aim of this present study is to evaluate urinary vanillylmandelic acid (VMA) levels in patients with generalized anxiety disorder.
\end{abstract}

Materials and methods: A cross-sectional study was performed in the Department of Physiology, Dhaka Medical College, Dhaka from July 2019 to June 2020.After obtaining ethical clearance, a total 144 individuals were selected based on inclusion and exclusion criteria with age ranging from 18-50 years. Group A was study group selected from Out Patient Department of Psychiatry of Dhaka Medical College Hospital, Dhaka diagnosed by the experienced psychiatrist. Group B was control group who were apparently healthy adults selected from different area of Dhaka city. The subjects were interviewed and detailed history regarding personal, family, medical and drug history were taken. Prior to sample collection, informed written consent was taken from the participants. Urinary vanillylmandelic acid levels were measured in the Department of Endocrinology, BIRDEM General Hospital, Dhaka.

Statistical analysis: For statistical analysis, Unpaired Student's ' $t$ ' test was considered using SPSS 25.0 version.

Results: Urinary vanillylmandelic acid of generalized anxiety disorder patients was significantly higher $(p<0.001)$ than control group.

Conclusion: It can be concluded that generalized anxiety disorder patients may have more chance of thrombotic diseases due to significantly higher urinary vanillylmandelic acid (VMA) levels than healthy adults.

Keywords: Generalized anxiety disorder (GAD); vanillylmandelic acid (VMA); Healthy adults; Physiology

\footnotetext{
${ }^{*}$ Corresponding author: Farzana Yeasmin Mukta

Department of Cardiology, Kurmitola General Hospital, Cantonment, Dhaka, Bangladesh.

Copyright $(2021$ Author(s) retain the copyright of this article. This article is published under the terms of the Creative Commons Attribution Liscense 4.0.
} 


\section{Introduction}

Now-a-days mental disorders are major public health problem in the world. Mental disorders are increasing in the developed countries as well as in developing countries and the prevalence rate is about 50\%. Among mental disorders the prevalence of anxiety disorder is common [1]. The prevalence of mental disorders is also high in Bangladesh. So psychiatric morbidity is a significant public health problem in Bangladesh [2]. Anxiety and stress stimulate blood catecholamine release and increase platelet activity and thus may play an important role in cardiovascular diseases such as myocardial infarction, ischemic heart disease, congestive heart failure, coronary artery disease, unstable angina etc [3].

Generalized anxiety disorder (GAD) is characterized by persistent and chronic worry that lasts for at least 6 months. It occurs most commonly in up to $21 \%$ of adults in their lifetime [4]. It can occur during stressful life circumstances such as family, financial, health, exam, future related problems etc. It has harmful effects on health. It aggravates physical diseases especially cardiovascular and cerebrovascular diseases [5].

Stressful life events and anxiety usually increase circulating blood catecholamine levels. Increased catecholamines are potent stimuli for platelets. They can activate platelet directly. Increased sympathetic activity causes excess secretion of catecholamines that can stimulate platelets via $\alpha-2$ adrenoceptors. Then the shape of platelet is changed from discoid to spherical and mean platelet volume values are also changed. Large platelets have greater thrombotic capability than small platelets [6,7]. Vizioli et al. (2009) also performed a study and found that anxiety cause increased sympathetic activity and thus cause higher mean platelet volume [8]. Thus, increased mean platelet volume is closely related with various cardiovascular diseases [9].

24-hour urinary vanillylmandelic acid is a metabolite of catecholamine. It is a marker of sympathetic activity. The half life of catecholamine is approximately 1-2 minutes. So, catecholamines are rapidly cleared off from circulation. Thus, we can measure catecholamine levels easily by 24-hour urinary vanillylmandelic acid levels [10].

Different researchers of various country performed studies to assess urinary vanillylmandelic acid levels in generalized anxiety disorder patients. A study among 14 generalized anxiety disorder patients revealed that plasma levels of catecholamines and their metabolites vanillylmandelic acid levels were significantly increased in generalized anxiety disorder patients compared to healthy controls [10]. Another study over 45 generalized anxiety disorder patients showed that increased urinary levels of vanillylmandelic acid were associated with severity of anxiety symptoms in generalized anxiety disorder patients [12]. Wingenfeid et al. (2015), Zhang et al. (2014), Hughes et al. (2004) also found similar observations $[13,14,15]$.

On the other hand, some researchers found no significant difference of urinary vanillylmandelic acid levels between generalized anxiety disorder patients and healthy subjects [16,17].

The present study was undertaken to evaluate urinary vanillylmandelic acid levels in generalized anxiety disorder patients and bring more awareness to prevent thrombotic diseases related morbidity.

\section{Material and methods}

\subsection{Study population and sample size}

This prospective type of analytical cross-sectional study was carried out in the Department of Physiology, Dhaka Medical College Hospital, Dhaka from July 2019 to June 2020. A total of 144 subjects, among them 72 newly diagnosed generalized anxiety disorder patients without previous history of drug intake by an experienced psychiatrist and 72 healthy individuals, aged ranging from 18-50 years were selected for this study.

\subsection{Grouping of the subjects}

Total 144 subjects divided into two groups.

Group A (study group): consisted of 72 newly diagnosed generalized anxiety disorder patients diagnosed according to the fifth edition of the Diagnostic and Statistical Manual of Mental Disorders (DSM-5) by an experienced psychiatrist. These patients had no previous history of anti-psychotic drug intake.

Group B (control group): consisted of 72 healthy individuals. 


\subsection{Procedure methodology}

After selection of the subjects, the nature, purpose and benefit of the study were explained to each subject in details. They were encouraged for voluntary participation. They were allowed to withdraw from the study whenever they feel like. Informed written consent was taken from the participants. The research work was carried out after obtaining ethical clearance from concerned departments, Research Review Committee and Ethical Review Committee of Dhaka Medical College, Dhaka. Study subjects and controls who were interested to take part in the study were requested to attend the Department of Physiology, Dhaka Medical College, Dhaka. Before taking sample, detailed personal, family, drug and medical history were taken. Anthropometric measurement of the study subjects and controls was done and blood pressure was measured. All the information's were recorded in a prefixed data collection form. The eligible subjects were advised to give sample. Total 144 subjects among them 72 newly diagnosed generalized anxiety disorder patients and 72 healthy subjects were selected for this study. Then both study subjects and controls were brought to the Department of Physiology, Dhaka Medical College Hospital, Dhaka and told to collect 24-hours urine from 6 am to 6 am in a 3-liter container. Then $3 \mathrm{ml}$ test tube was used to collect urine for urinary vanillylmandelic acid test and send to Department of Endocrinology, BIRDEM General Hospital, Dhaka. Urinary vanillylmandelic acid test was done by ELISA method.

\subsection{Statistical analysis}

The parameter was expressed as mean \pm SD (standard deviation). Unpaired Student's ' $t$ ' test was performed to compare between two groups. The $p$ value $<0.05$ was accepted as level of significance. Statistical analysis was performed by using a computer based statistical program SPSS (Statistical package for social science) version 25.0.

\section{Results and discussion}

The mean $( \pm$ SD) urinary vanillylmandelic acid was $15.39 \pm 1.59 \mathrm{mg} /$ day in study group and $7.16 \pm 0.63 \mathrm{mg} /$ day in control group. The mean $( \pm S D)$ urinary vanillylmandelic acid was higher in study group than control group which was statistically significant $(p$ value $=0.001)$.

Table-I Urinary vanillylmandelic acid levels in both groups ( $\mathrm{N}=144)$

\begin{tabular}{|l|c|l|l|}
\hline Parameter & $\begin{array}{l}\text { Group A } \\
\left(\mathbf{n}_{\mathbf{1}}=\mathbf{7 2}\right)\end{array}$ & $\begin{array}{l}\text { Group B } \\
\left(\mathbf{n}_{\mathbf{2}}=\mathbf{7 2}\right)\end{array}$ & $\boldsymbol{p}$ value \\
\hline Urinary vanillylmandelic acid (VMA) (mg/day) & $15.39 \pm 1.59$ & $7.16 \pm 0.63$ & $0.001^{*}$ \\
\hline
\end{tabular}

Data were expressed as mean \pm SD; Unpaired Student's ' $t$ ' test was performed to compare between two groups; *significant $\mathrm{N}$ : Total number of subjects; $\mathrm{n} 1$ : Number of subjects in group A; $n 2$ : Number of subjects in group B; Group A (Study group): Generalized Anxiety Patients; Group B (Control group): Heathy Subjects

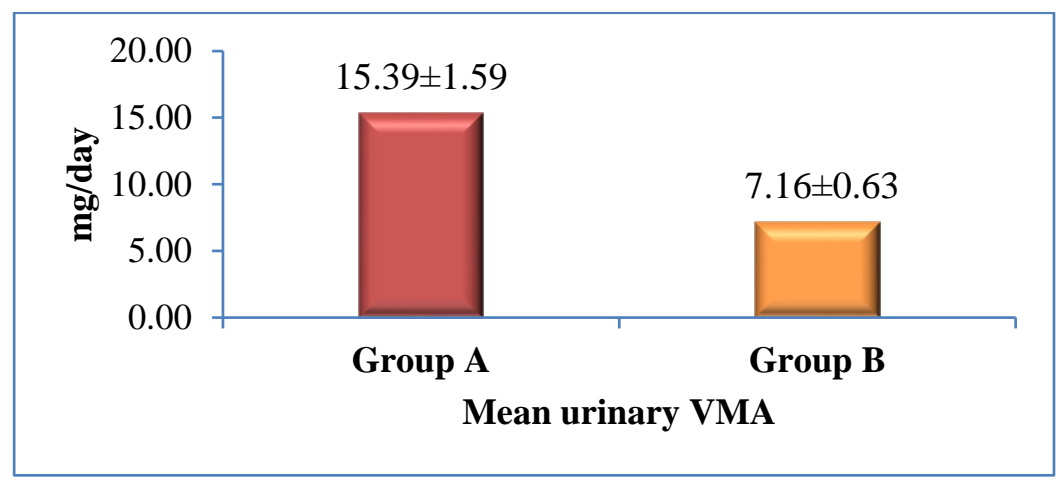

Figure 1 Mean urinary vanillylmandelic acid (mg/day) of the subjects in both groups ( $N=144) . N$ : Total number of subjects; Group A: Generalized anxiety disorder patients; Group B: Healthy subjects 


\section{Discussion}

The current study was undertaken to assess the urinary vanillylmandelic acid levels in generalized anxiety disorder patients. For this reason, a total 144 subjects age ranging from 18 to 50 years included in this study on the basis of inclusion and exclusion criteria. Among them, 72 newly diagnosed generalized anxiety disorder patients were selected as study group and 72 healthy subjects were selected as control group.

In the present study, table I and figure-1 show that the mean urinary vanillylmandelic acid levels of the study group were slightly raised from the upper limit of normal range and control groups were within normal range. The mean urinary vanillylmandelic acid level was significantly higher in study group than controls. Almost similar types of results were observed by different researchers [12,13]. In general, epinephrine from adrenal medulla is the hallmark of acute stress and anxiety which is accompanied by release of noradrenaline. A possible explanation for this is the over activation of noradrenaline receptors in amygdala, hippocampus, hypothalamus. striatum and prefrontal cortex. So, more noradrenaline can bind with receptors and gives the symptoms of anxiety. As platelets contain $\alpha-2, \beta-2$ receptors same as brain they are called mirror of brain function. When noradrenaline binds with receptors in brain they also bind with platelet $\alpha-2$ receptor. Thus, platelets are stimulated and become more active. So, there is increased chance of thrombosis $[13,14]$.

On the other hand, Osuch et al. (2009) found lower urinary catecholamine excretion in anxiety disorder than healthy controls which was statistically significant [16]. Videlock et al. (2008) observed similar level of urinary vanillylmandelic acid in anxiety disorder and healthy adults. This disagreement was due to down regulation of the catecholamine receptors in the central nervous system as well as in platelets. They also explained that impairment of baroreceptor reflex occurred under anxiety and stress. This could reduce inhibitory effect of vagus nerve on sympathetic system activity. This might be the cause of contrary in findings [17].

This present study had some limitations, Samples were taken purposively so that there may be chance of bias which can influence the results. More investigations like inflammatory markers (IL-1,6, TNF) and serotonin levels could not be measured due to financial constraints, time and lack of availability.

\section{Conclusion}

After analyzing the results of the study, it can be concluded that patients with generalized anxiety disorder may have more future risk of thrombosis due to significantly higher level of urinary vanillylmandelic acid than healthy adults.

\section{Compliance with ethical standards}

\section{Acknowledgments}

The authors acknowledge Department of Endocrinology, BIRDEM General Hospital, Dhaka for their kind cooperation.

\section{Disclosure of conflict of interest}

The authors declare no conflicts of interest regarding the publication of this paper.

\section{Statement of ethical approval}

Ethical clearance of this study was obtained from concerned Departments, Research review committee and Ethical review committee of Dhaka Medical College, Dhaka.

\section{Statement of informed consent}

Informed written consent was taken from all the participants including both study group and control group.

\section{References}

[1] Sansone RA, Sansone LA. Psychiatric Disorders: A Global Look at Facts and Figures. Psychiatry, 2010; 7(12):1619. 
[2] Islam A, Biswas T. Mental health and the health system in Bangladesh: Situation analysis of a neglected Domain. American Journal of Psychiatry and Neuroscience, 2015; 3(4):57-62.

[3] Markovitz JH, Matthews KA. Platelets and coronary heart disease: potential psychophysiologic mechanisms. Psychosomatic Medicine, 1991; 53(1):643-668.

[4] Moffitt TE, Caspi A, Taylor A, Kokaua J, Milne BJ, Polanczyk G, Poulton R. How common are common mental disorders? Evidence that lifetime prevalence rates are doubled by prospective versus retrospective ascertainment. Psychological Medicine, 2010; 40(6):899-909.

[5] Stein MB, Sareen J. Clinical Practice. Generalized anxiety disorder. New England Journal of Medicine, 2015; 373(21):2059-2068.

[6] Almis BH, Aksoy I. Mean platelet volume levels in patients with generalized anxiety disorder. Psychiatry and Clinical Psychopharmacology, 2018; 28(1):43-47.

[7] Durmaz T, Ozdemir 0, Keles T, Bayram NA, Akcay M, Yeter E, Ayhan H, Bozkurt E. Platelets and sympathetic activity in MI. Turkey Journal of Medical Science, 2009; 39(2):259-265.

[8] Vizioli L, Muscari S, Muscari A. The relationship of mean platelet volume with the risk and prognosis of cardiovascular diseases. International Journal of Clinical Practice, 2009; 63(1):1509-1515.

[9] Bondade S, Supriya, Seema SM, Shivakumar BK. Mean platelet volume in depression and anxiety disorder-a hospital based case-control study. International Neuropsychiatric Disease Journal, 2018; 11(4):1-8.

[10] Berry W, Mckenzie C. Use of inotropes in critical care. Clinical Pharmacist, 2010; 2 (1):395.

[11] Sevy S, Papadimitriou GN, Surmont DW, Goldman S, Mendlewicz J. Noradrenergic function in generalized anxiety disorder, major depressive disorder and healthy subjects. Biological Psychiatry, 1989; 1(1):142-152.

[12] Garvey MJ, Noyes R, Woodman C, Laukes C. Relationship of generalized anxiety disorder symptoms to urinary 5hydroxyindoleacetic acid and vanillylmandelic acid. Neuropsychiatry, 1995; 31(1):6-9.

[13] Wingenfeid K, Whooley MA, Neylan TC, Otte C, Cohen B.E. Effect of current and lifetime posttraumatic stress disorder on 24-h urinary catecholamines and cortisol. Psychoneuroendocrinology, 2015; 52(1):83-91.

[14] Zhang GQ, Yang JX, Zhang YQ, Liang X, Hu M, Fan J. Altered Neurotransmitter levels with posttraumatic stress disorder. Turk. Neurosurg, 2014; 246(1):844-848.

[15] Hughes JW, Watkins L, Blumenthal JA, Kuhn C, Sherwood A. Depression and anxiety symptoms are related to increased 24-hour urinary noradrenaline excretion among healthy middle-aged women. Journal of Psychosomatic Research, 2004; 57(1):353-358.

[16] Osuch AE, Benson EB, Luckenbaugh AD, Geraci M, Post MR, Mccann U. Repetitive TMS combined with exposure therapy for PTSD: a preliminary study. Journal of Anxiety Disorder, 2009; 23(1):54-59.

[17] Videlock JE, Peleg T, Segman R, Rachel Y, Pitman KR, Shalev YA. Stress hormones and posttraumatic stress disorder in civilian trauma victims. International Journal of Neuropsychopharmacology, 2008; 11(3):373-380. 